\title{
New WHO guidelines on paediatric mortality and morbidity auditing
}

Trevor Duke, ${ }^{\oplus 1,2}$ Grace Irimu, ${ }^{3,4}$ Wilson Were ${ }^{5}$

It is tragic when a child dies, for the parents, the extended family and the community. It is also sad for the healthcare workers who have been caring for the child.

Although substantial progress has been made in reducing child deaths globally since 1990 , many preventable child deaths still occur due to poor quality of care and adverse social and environmental circumstances. Mortality audit and review can help us learn important lessons from child deaths that can guide quality improvement and public policy. It is not new: child death review began in the USA in the 1970s, is a statutory requirement in England and New Zealand and is being implemented at a national level in several other high-income countries, including Australia, Canada, the Netherlands and Wales. ${ }^{1-3}$ In South Africa, Papua New Guinea and Solomon Islands, and a small number of other low/middle-income countries, mortality auditing has been used to initiate improvements in paediatric hospital care. ${ }^{4-9}$ The reasons why this has not been done at large scale in the past are several: lack of time, given the high burden of caring for the living; the large number of child deaths in some health facilities and not knowing where to start; fear of blame if audit is conducted in an inappropriate, punitive or insensitive way; difficulty in complying with international coding systems; lack of inclusion of this skill in health training colleges; lack of follow-up of actions; and uncertainty about how to do it. Until now there has been no guidance on how to conduct child mortality and morbidity

${ }^{1}$ Intensive Care Unit and University of Melbourne Department of Paediatrics, Royal Children's Hospital, Parkville, Victoria, Australia

${ }^{2}$ Child Health, School of Medicine and Health Sciences, University of Papua New Guinea, Port Moresby, National Capital District, Papua New Guinea

${ }^{3}$ Pediatrics, University of Nairobi, Nairobi, Kenya ${ }^{4}$ Health Services Unit, Centre for Geographic Medicine Research Coast, Nairobi, Kenya

${ }^{5}$ Maternal, Child and Adolescent Health, World Health Organization, Geneva, Switzerland

Correspondence to Professor Trevor Duke, Intensive Care Unit and University of Melbourne Department of Paediatrics, Royal Children's Hospital, Parkville VIC 3052,Australia; trevor.duke@rch.org.au auditing, now the WHO has this in a new publication, ${ }^{10}$ available at https://www. who.int/maternal_child_adolescent/ documents/improving-quality-paediatric-care/en/.

Mortality auditing and review can occur at both a clinical level in hospitals and health facilities, and a public health or jurisdictional level, to provide advice to governments, healthcare workers and community stakeholders on how to prevent deaths in the future. Deaths may be audited, and sentinel adverse events or near misses, or cases that have gone well.

The essence of audit is telling an accurate story and discussing how to avoid a similar death or adverse outcome in the future. Audit fulfils an obligation for us to continuously learn and improve quality of a care. If conducted properly and in a sensitive way, audit provides an opportunity for reflection, support and education for healthcare workers. Audit is also helpful for bereaved families to know that their child's life was important, and their death is being taken seriously, and to know that we are committed to learning and improving wherever possible.

Mortality review requires assigning causes to each death. The International Classification of Diseases (ICD) in its most current revision (ICD-11) is recommended by WHO as a uniform approach to the classification of diseases, which makes it comparable across settings. However, ICD has over 60000 diagnostic codes $^{11}$ and thus requires training to develop competence in coding. In most low/middle-income countries full compliance with precise and accurate ICD coding is hampered by limited resources for record keeping and lack of diagnostic capacity. There are now tools available to record common diagnoses and cause of death, consistent with ICD-11 coding. ${ }^{12}$ A simplified list of diagnoses and causes of death, which are clinical in nature and do not require specialised testing or postmortem examination, is provided in the WHO guidelines. ${ }^{10}$

Considering only one cause of death is often misleading, as children may have one acute illness, one or more underlying or associated conditions or comorbidities, and have adverse social or environmental circumstances that are all part of the causal pathway to the child's death. Also, modifiable factors-factors which may be modified and prevent a death in the future-may be present at any level. Useful ways to classify deaths are:

- Immediate cause of death (the acute illness leading to death).

- Underlying chronic conditions or comorbidities.

- Other associated diagnoses, and social and environmental risk factors.

There are several ways to classify modifiable factors. The guide proposes a simplified approach. ${ }^{10}$ These include: modifiable factors in the community, including care seeking, social and environmental risk factors, primary care or referral systems, modifiable factors in hospital, such as lack of triage or delayed emergency treatment, problems with clinical assessment, diagnosis and treatment, problems with monitoring and supportive care, hospital-based prevention failure and specific complications of treatment or hospitalisation, such as hospital-acquired infections, intravenous drip complications, progressive malnutrition while in hospital and medication and procedural errors. Audit should be system focused and also identify clinical lessons that we all can learn from, it should not be focused on individual actions. Principles of clinical audit are described in the Panel. Tailoring the methodology of mortality audit or death review to the location is essential.

An essential part of audit is follow-up and action, and for this a quality improvement team is useful. Follow-up on all actions is too much for any one individual, and many recommendations require a small team, made up of enthusiastic doctors and nurses, and other disciplines. Sometimes the actions require multisector approaches, where actions will be at a public or community level, and require involvement of officials who are responsible for roads, education, social welfare, water and sanitation, and health facility infrastructure.

Archives of Disease in Childhood is keen to publish experiences of paediatricians in using the WHO guidelines in low/middle-income countries that provide insights into the effectiveness of audit and how to do it better.

\section{PRINCIPLES OF WELL-FUNCTIONING CHILD MORTALITY AND MORBIDITY REVIEW MEETINGS}

There are many ways to conduct meetings, but it is useful to have some principles: 
- Hold regular meetings: sustainability is dependent on commitment by staff to be present at a regular time every week or month.

- Confidentiality: encourage open discussion inside the meeting, but no discussion of specific cases outside.

- Attendance is voluntary, but openly encourages all staff to attend. Audits should not be an exclusive activity for medical staff, but require active and voluntary participation of all clinical staff and relevant technical staff.

- Feedback to and involvement of all staff is important.

- Be non-blameful and non-threatening, and welcoming to all staff.

- The team leader should be open about declaring his/her own failings. This can put junior staff at ease.

- Audit meetings should have a strong educational aspect; take the opportunity to teach on subjects that arise when they are relevant to quality of care.

- Use a team approach in identifying and solving problems: seek a wide spectrum of views on modifiable factors and solutions.

- Be respectful and acknowledge all health workers' efforts. Try to understand how they are feeling.

- Move from specific cases to general issues.

- Encourage good documentation, which is essential for accurate data collection and communication.
- Look for common patterns of avoidable events; do not just react to a single rare mistake or event.

- Do not single out individuals for blame. The team leader should emphasise system changes and the lessons from which everyone can learn. Modifiable factors should be viewed as offering opportunities for improvement.

- Consider the entire health system when trying to understand modifiable factors in deaths, not just referral-level hospital care.

Contributors TD wrote the editorial. GI and WW reviewed and made changes. All three authors had input into the content and approved the final version.

Funding The authors have not declared a specific grant for this research from any funding agency in the public, commercial or not-for-profit sectors.

Competing interests None declared.

Patient consent for publication Not required.

Provenance and peer review Not commissioned; internally peer reviewed.

C Author(s) (or their employer(s)) 2019. No commercial re-use. See rights and permissions. Published by BMJ.

\section{(D) Check for updates}

To cite Duke T, Irimu G, Were W. Arch Dis Child 2019;104:831-832.

Received 31 January 2019

Revised 4 February 2019

Accepted 5 February 2019

Published Online First 12 March 2019

Arch Dis Child 2019;104:831-832.

doi:10.1136/archdischild-2019-316956

\section{REFERENCES}

1 World Health Organization. Making every baby count: audit and review of stillbirths and neonatal deaths. 2016 https://www.who.int/maternal_child_ adolescent/documents/stillbirth-neonatal-deathreview/en/ (Accessed 5 Feb 2019).

2 Sidebotham P, Fraser J, Covington T, et al. Understanding why children die in high-income countries. Lancet 2014:384:915-27.

3 Frey B, Doell C, Klauwer D, et al. The morbidity and mortality conference in pediatric intensive care as a means for improving patient safety. Pediatr Crit Care Med 2016;17:67-72.

4 Krug A, Pattinson RC, Power DJ. Saving children-an audit system to assess under-5 health care. S Afr Med J 2004;94:198-202.

5 Krug A, Pattinson RC, Power DJ. Why children die: an under-5 health care survey in Mafikeng region. SAfr Med J 2004;94:202-6.

6 Krug A, Patrick M, Pattinson RC, et al. Childhood death auditing to improve paediatric care. Acta Paediatr 2006;95:1467-73.

7 Duke T, Michael A, Mgone J, et al. Etiology of child mortality in Goroka, Papua New Guinea: a prospective two-year study. Bull World Health Organ 2002;80:16-25.

8 Nasi T, Vince JD, Mokela D. Mortality in children admitted to Port Moresby General Hospital: how can we improve our hospital outcomes?. P N G Med J 2003:46:113-24.

9 Sandakabatu M, Nasi T, Titiulu C, et al. Evaluating the process and outcomes of child death review in the Solomon Islands. Arch Dis Child 2018;103:685-90.

10 World Health Organization. Improving the quality of paediatric care: an operational guide for facilitybased audit and review of paediatric mortality, 2018.

11 Centres for Disease Control. International Classification of Diseases (ICD-10-CM/PCS). 2016 http://www.who. int/classifications/icd/en/.

12 Duke T, Yano E, Hutchinson A, et al. Large-scale data reporting of paediatric morbidity and mortality in developing countries: it can be done. Arch Dis Child 2016;101:392-7. 